\title{
ORGANOCHLORIDE PESTICIDES IN MACEDONIAN GIRLS WITH PREMATURE SEXUAL DEVELOPMENT
}

\author{
Krstevska-Konstantinova $\mathrm{M}^{1, *}$, Kocova $\mathrm{M}^{1}$, Charlier $\mathrm{C}^{2}$, Bourguignon $\mathrm{JP}^{3}$
}

*Corresponding Author: Dr. Marina Krstevska Konstantinova, Pediatric Clinic, Department of Endocrinology and Genetics, Medical Faculty, Vodnjanska 17, 1000 Skopje, Republic of Macedonia; Tel.: +389-2-314-7474; Fax:+389-2-3225-809; E-mail: marina@lancom.com.mk

\begin{abstract}
Premature sexual development (PSD) in girls describes the appearance of secondary sexual signs before the age of 8 years. Early puberty is diagnosed if pubertal signs appear between the age of 8 and 9 years. We found a positive association between the levels of organochloride pesticides (p,p'-DDE) in precocious puberty in girls adopted from developing countries and significantly higher levels than in native Belgian girls with the same condition.

We have compared the serum levels of eight $p, p$ 'DDE in 56 Macedonian girls with PSD and a control group of 24 normal, age-matched girls, using a gas chromatographic analyzer coupled to a tandem mass spectrometer detector. Of the 56 girls with PSD, 42 had premature thelarche, five had early puberty, and nine had precocious puberty of idiopathic $(n=8)$ or organic $(n=1)$ origin. We found traces of $\mathrm{p}, \mathrm{p}$ DDE in nine girls $(16 \%)$ and negative results in 41 $(73 \%)$, while the remaining six $(10 \%)$ had a mean level of $1.17 \pm 0.7 \mu \mathrm{g} / \mathrm{L}$. In the control group, traces were found in one girl (4\%) and negative results in $18(75 \%)$, while the remaining five $(20 \%)$ had a mean level of $1.18 \pm 0.6 \mu \mathrm{g} / \mathrm{L}$. We found elevated levels of lindane in the girls with PSD (mean value

1 Pediatric Clinic, Department of Endocrinology and Genetics, Skopje, R. Macedonia

${ }^{2}$ Laboratory of Toxicology, University of Liège, C.H.U. Sart Tilman, Liège, Belgium

${ }^{3}$ Division of Ambulatory Pediatrics and Adolescent Medicine, Department of Pediatrics, University of Liege, C.H.U. Sart Tilman, Liège, Belgium
\end{abstract}

$1.2 \pm 0.8)$ and significantly higher levels in the control group $(1.4 \pm 0.8)(p<0.05)$. We concluded that Macedonian girls with PSD do not have higher levels of p,p'-DDE in their serum than the normal controls. However, the elevated levels of lindane in this population should be further investigated.

Key words: Organochloride pesticides (p,p'DDE); Premature sexual development (PSD)

\section{INTRODUCTION}

Puberty is a very important phase in the process of becoming an adult, because secondary sexual characteristics appear, a growth spurt occurs, fertility is achieved and significant psychological changes occur. The mean age of menarche in several developed countries of Europe and the USA, decreased from the mid-1800s to mid-1900s [1].This effect is thought to result from improved socio-economic factors, health, nutrition, and the gains of urbanization [2]. We found a positive association between the levels of organochloride pesticides ( $\mathrm{p}, \mathrm{p}$ '-DDE) in precocious puberty in girls adopted from developing countries and significantly higher levels than in native Belgian girls with the same condition [3].

In premature sexual development (PSD) the appearance of secondary sexual characteristics occurs before the age of 8 years in girls. Sexual development that results from premature activation of the hypothalamic pulsatile generator-pituitary gonadotropin-gonadal axis is considered as a complete isosexual development, or true central precocious puberty. When secretion of gonadotropins 
or gonadal steroids occurs independently of the pulsatile gonadotropin-releasing-hormone (GNRH) generator, it is considered to be a pseudo-precocious puberty. Early puberty occurs between the age of 8 and 9 years in girls. An isolated growth of breasts in girls represents premature thelarche [4].

Although improved nutrition leads to earlier puberty [5], exposure to endocrine disruptors may contribute for earlier appearance to the puberty or other pubertal disturbances [3,6-8]. Children from developing countries adopted in Western countries often develop PSD [9-11]. Precocious puberty has been described after accidental exposure to estrogenic compounds in cosmetic products, food, or pharmaceutical products [12]. In our Belgian study, we investigated whether exposure to p,p'-DDE may lead to PSD [3].

Endocrine disruptors are synthetic chemicals that, on absorbtion into the body, either mimic or block hormones and disrupt the body's normal functions [13]. They include certain pesticides (DDT), industrial chemicals (PCBs, dioxins), phthalates, phenols (bisphenol A, alkylphenol) and plant hormones (phytoestrogens). Delayed puberty has been associated with exposure to endocrine disruptors [7], of which some may have intrinsic estrogen activity or increase endogenous sex hormone levels [13]. These effects have been documented at extremely low doses [13], which are thought to be safe, but produce undesirable effects in animal studies. In rats, minimal doses of bisphenol A that is present in plastics, produce structural abnormalities of the vagina and uterus [14]. Some forms of DDT and other pesticides and industrial chemicals such as PCBs, increase the wet weight of the virgin mouse uterus, the classic bioassay for estrogenicity [15].

Adolescence, with its increased levels of hormonesneededforsexualdevelopment,is especially vulnerable to these substances. This increase in hormone levels may cause the development of hormone-dependent cancers, especially if associated with exposure to phytoestrogens or other endocrine disruptors [16]. Girls are in greater danger because they have a larger amount of fat tissue in which the disruptors are stored. Early or delayed puberty may result from endocrine disruptors and may become a difficult emotional problem, since young girls lack the socialization and self-confidence of older children. The health effects associated with PSD in girls in later life are: increased risk of breast cancer and polycystic ovary disease (PCOS), inadequate behavior, acne and hirsutism.

\section{MATERIALS AND METHODS}

Girls with PSD $(n=56)$, aged between 2 and 9 years, referred by their primary care pediatricians from all over the Republic of Macedonia, including the capital city of Skopje, were recruited following clinical evaluation at the Department for Endocrinology and Genetics and the Pediatric Clinic, Medical Faculty in Skopje. Blood samples were obtained at the time of diagnosis. The control group consisted of 24 normal healthy girls from different regions in the Republic of Macedonia, age-matched with the PSD group, who were evaluated at the Pediatric Clinic, for clinical conditions such as upper respiratory infections or pulmonary infections. Analysis for p,p'DDE was performed at the Toxicology Department of C.H.U. Sart Tilman in Liege, Belgium.

Concentration of p,p'-DDE in serum were measured using a gas chromatographic analyzer coupled to a tandem mass spectrometer detector. The following pesticides were also measured: DDT, lindane, arachlor, heptachlor, aldrin, endrin and hexachlorbenzene (HCB). Sample preparation included a liquid-liquid extraction (petroleum ether: diethyl ether; 98:2) followed by a solid phase extraction (Bond Elut Certify; Varian, Walnut Creek, CA, USA). The eluate was evaporated to dryness and reconstituted with the derivatization mixture [N, O-bis (trimethylsilyl) trifluoroacetamide (BSTFA)/trimethylchlorosilane (TMCS) $10 \%$ in n-hexane] before injection into the gas chromatograph (Saturn 2000; Varian). The column was an HP-5 Trace (30 $\mathrm{m} \times 0.25 \mathrm{~mm}$ internal diameter) from Hewlett Packard (Wilmington, DE, USA). Ionization by electronic impact occurred at $70 \mathrm{eV}$. All solvents were pesticide-grade quality. Reference standards were obtained from Cambridge Isotope Laboratories (Andover, MA, USA). A calibration curve was constructed over the range from 0 to 40 $\mathrm{ppb}$, and showed linearity. Endosulphan-d4 (0.5 ppb) was used as internal standard. The recovery of p,p'DDE was $96 \%$. The limit of detection $(0.1 \mathrm{ppb})$ was defined as three times the standard deviation (SD) of the results from the lowest quality-control serum pool over the course of the analyses $(n=15)$. For p,p'-DDE, this was consistent with a detection limit of $0.1 \mathrm{ng} / \mathrm{mL}$ serum. The coefficients of variation were between 4.6 and $7.8 \%$. 


\section{RESULTS}

Most girls who had PSD and the girls in the control group came from the capital, Skopje, and also from towns in the Republic of Macedonia. They were referred to the Pediatric Clinic by their family doctors. Figure 1 shows the towns in the Republic of Macedonia from which the girls (and numbers) originate.

Of the 56 girls with PSD, 42 had premature thelarche, five had early puberty, and nine had precocious puberty of idiopathic $(n=8)$ or organic $(n=1)$ origin. Traces of $\mathrm{p}, \mathrm{p}$ '-DDE were found in nine girls (16\%), while $41(73 \%)$ had negative results and six $(10 \%)$ had a mean value of $1.17 \pm 0.7$ $\mu \mathrm{g} / \mathrm{L}$. In the control group, traces of $\mathrm{p}, \mathrm{p}$ '-DDE were found in one girl (4\%), while 18 had negative results $(75 \%)$ and five $(20 \%)$ had a mean level of $1.18 \pm 0.6$ $\mu \mathrm{g} / \mathrm{L}$. There were no significant differences between the levels of p,p'-DDE in both groups. PSD: $\mathrm{P} 1=$ $14 / 56=0.25$; controls: $\mathrm{P} 2=6 / 4=0.25, \mathrm{P} 1-\mathrm{P} 2=0$.

The mean level of lindane in the PSD group was $1.2 \pm 0.8 \mu \mathrm{g} / \mathrm{L}$, and in the control group $1.4 \pm$ $0.8 \mu \mathrm{g} / \mathrm{L}$. A significantly larger proportion of girls who tested positive for lindane in the control group $(p<0.05)$ than in the PSD group $(\mathrm{t}=0.39 / 0.121=$
$3.233 t$-test). This comparison was performed using unpaired Student's $t$-test. PSD: P1 $=18 / 56=0.32$; controls: $\mathrm{P} 2=17 / 24=0.71, \mathrm{P} 1-\mathrm{P} 2=0.32-0.71=$ (0.39), S P11p $=0.121$ (standard error for both groups). Figure 2 shows the levels of lindane and $\mathrm{p}, \mathrm{p}$ '-DDE in the PSD and control group.

\section{DISCUSSION}

Our previous study [3], showed that foreign adopted children and non adopted girls with precocious puberty tested for eight pesticides, detected p,p'-DDE, which is derived from the organochloride pesticide DDT, while Belgian girls with idiopathic or organic precocious puberty showed undetectable concentrations. A possible relationship between transient exposure to endocrine disruptors and sexual precocity was suggested [3]. This hypothesis was further investigated in our country, where we evaluated 56 girls with PSD for the presence of p,p'-DDE compared to a control group of 24 healthy girls. We expected to obtain results that would show higher pesticides levels in the girls with PSD, but our results did not confirm our hypothesis. We were surprised to find increased levels of lindane in both groups of girls in our population, which was not registered in

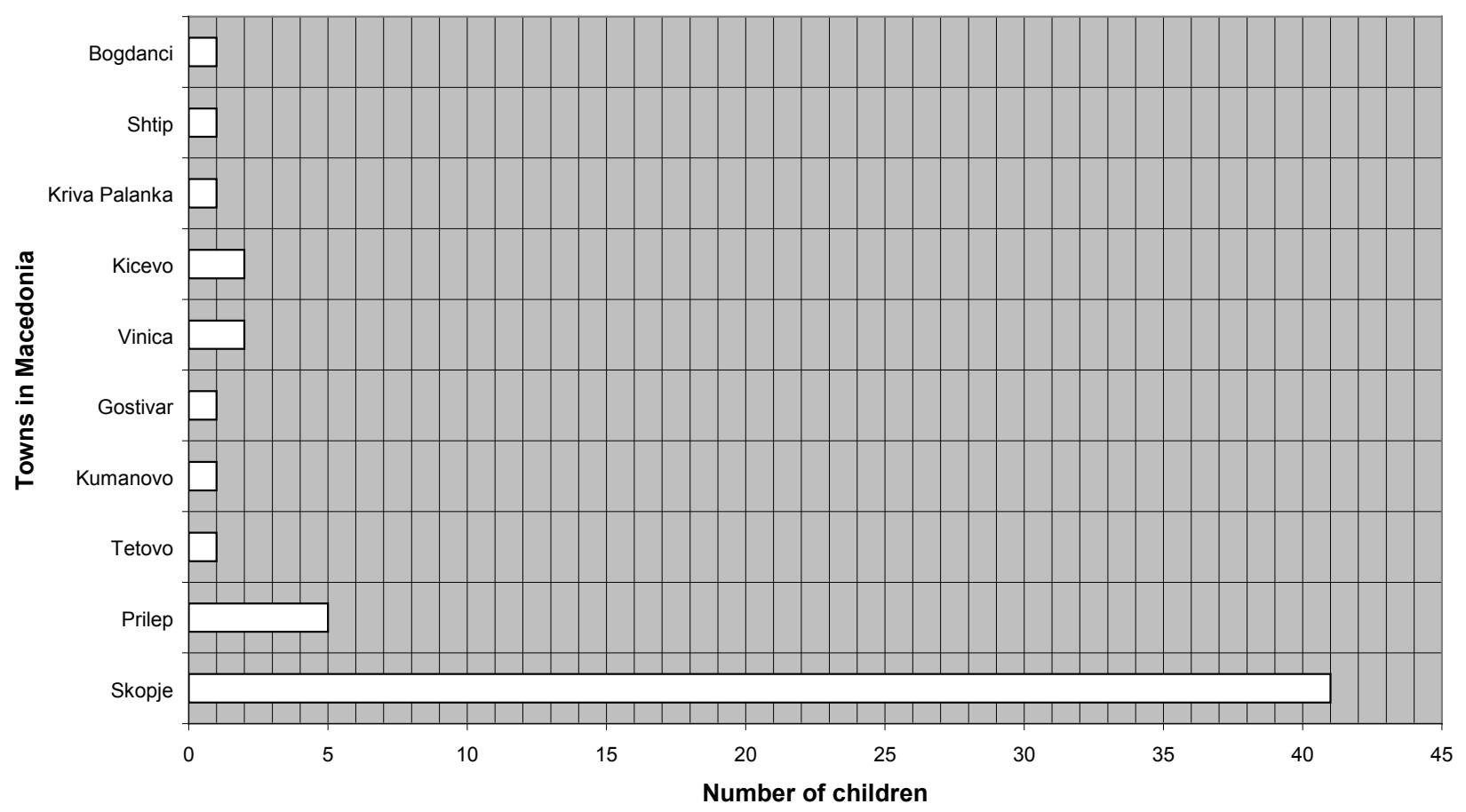

Figure 1. Distribution of children with PSD by regions in the Republic of Macedonia. 
Lindane $\mu \mathrm{g} / \mathrm{l}$

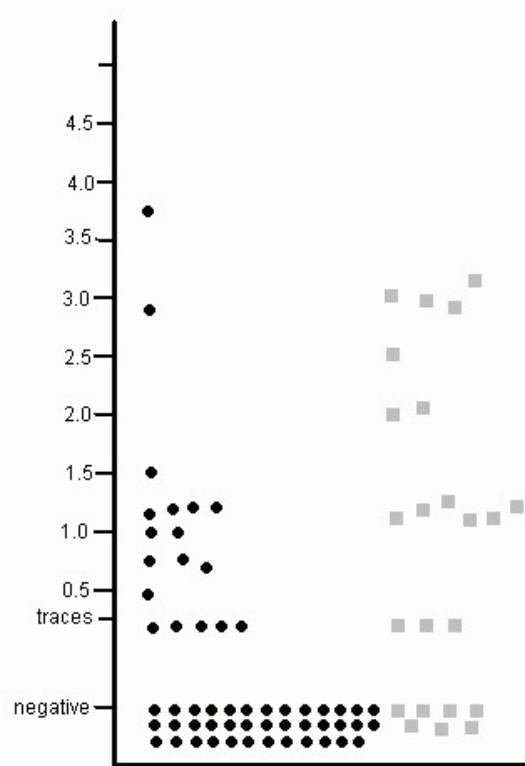

P.P-DDE $\mu g / l$

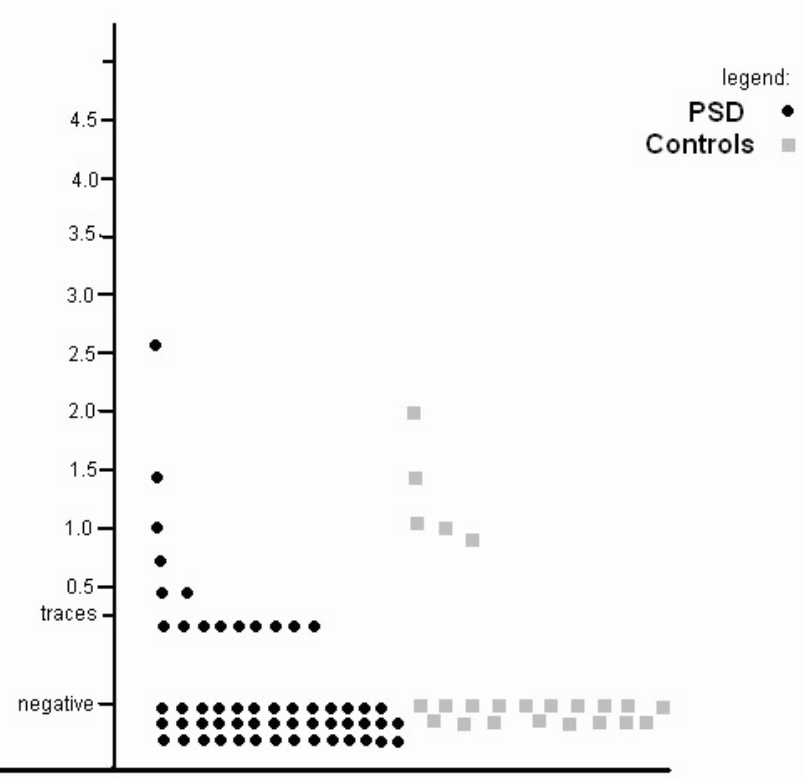

Figure 2. Individual values of lindane and p,p'-DDE in PSD girls and controls.

the Belgian study. The levels of p, p'-DDE in our two groups of girls were similar to those in the adopted and non adopted foreign girls in Belgium. Two hypotheses were tested for the appearance of PSD in relation to xenoestrogens. One concentrated on the mechanism through which xenoestrogens, having estrogenic effect, weakly stimulate the estrogen-sensitive tissues including the hypothalamus, and enhance its maturation with the consequence of PSD. The weak stimulation of estrogen-sensitive tissues may occur peripherally, as seen in the epidemic of PSD, possibly influenced by xenoestrogens [12]. The stimulation of estrogen-sensitive tissues may also occur centrally. The other hypothesis suggests that an environment which is pesticide-free, while moving from an environment where they are present, may trigger the appearance of PSD. In the environment where the xenoestrogens are present, a negative gonadotropin feed-back inhibition exists. It is a well known central effect of estrogens in pre pubertal children $[17,18]$.

The DDT isomers o,p'-DDT, o,p'-DDE and p,p'-DDT exhibit weak estrogenic activity in many systems, for example, the rat uterus $[19,20]$. Some estrogenic and anti-androgenic effects of $\mathrm{p}, \mathrm{p}$ '-DDE have been reported in salamanders [21]. The results of Charlier [22], suggest that environmental exposure to $\mathrm{p}, \mathrm{p}$ '-DDE, HCB, or PCBs may contribute to the pathogenesis of breast cancer and male infertility, and that deleterious effects are probably restricted to intra- uterine life. Diethylstilbestrol (DES) and o,p'-DDT given to pubertal rats act as estrogenic morphogens; i.e., they increase cell proliferation, which promotes maturation of the undifferentiated terminal end buds to more differentiated lobular terminal ductal structures [23]. Pathological variations in the timing of puberty may provide unique information about the interactions of environmental conditions or of genetic susceptibility with the hypothalamic mechanism that controls the onset of sexual maturation, as shown by examples of precocious puberty following exposure to endocrine disruptors or due to hypothalamic hamartoma [24].

Other substances also affect the timing of puberty. Early puberty was more common in daughters of mothers exposed to polybrominated biphenyl or PBB while breast-feeding their daughters. Menarche occurred in these girls with a mean of 11.6 years, compared to 12.7 years in the normal population [8]. In a study of 594 girls, it was seen that girls who had the highest level of PCB reached puberty earlier than their peers [25], while a study of 41 girls with premature thelarche showed that $68 \%$ had increased levels of phthalates, present in plastics, in comparison to a healthy control group [26].

Delayed puberty has also been reported after exposure to endocrine disruptors. A study of 3,000 girls from different ethnic groups in the USA found that increased concentrations of copper in 
the environment may result in delayed growth and puberty in girls [7]. The effect of polychlorinated aromatic hydrocarbonates (PCAH) on sexual maturation among 200 urban adolescents was evaluated and compared in rural adolescents; only those boys or girls who had elevated concentrations of the chemical experienced delayed puberty [27].

The use of DDT has been banned in West European countries and the USA for almost four decades [28]. A proposal has been presented to the World Health Organization (WHO) and the Food and Agriculture Organization (FAO) to develop a minimum list of pesticides which are not hazardous for human health [29]. In the Republic of Macedonia, the law on Plant Protection banned the application of Persistent Organic Pollutants (POPs) from 1982. Six of the nine POP pesticides are subject to the "Rotterdam Convention on the Prior Informed Consent (PIC) Procedure for Certain Hazardous Chemicals and Pesticides in International Trade" in which the Republic of Macedonia was included in 2001. However, they remain in limited use, legally and illegally. The last application of DDT as an insecticide in the Republic of Macedonia was recorded in 1976 for plant protection of the forests [30].

\section{CONCLUSIONS}

Our study showed that Macedonian girls with PSD do not have increased levels of p,p'-DDE and lindane, which could be a reason for their sexual precocity, compared to the control group. Girls in the Republic of Macedonia with PSD have similar levels of pesticides in their serum as the adopted immigrant girls in our Belgian study [3]. Further studies are needed to determine if eventual pubertal disturbances have occurred in girls from the Republic of Macedonia who had moved to a western country.

\section{ACKNOWLEDGMENTS}

We wish to thank Professor Corrine Charlier and the Department for Toxicology and Professor JeanPierre Bourguignon at the Division of Ambulatory Pediatrics and Adolescent Medicine, University of Liege, C.H.U. Sart Tilman, Liege, Belgium, for generously performing the necessary pesticide investigation in our patients. We are grateful for their enthusiasm in this study and in the discussion of results.

\section{REFERENCES}

1. Ritzen EM. Early puberty: what is normal and when is treatment indicated? Horm Res 2003; 60 (Suppl 3): 31-34.

2. Wyshak G, Frisch RE. Evidence for a secular trend in age of menarche. N Engl J Med 1982; 306(17): 1033-1035.

3. Krstevska-Konstantinova M, Charlier C, Craen M, Du Caju M, Heinrichs C, de Beaufort C, Plomteux G, Bourguignon JP. Sexual precocity after immigration from developing countries to Belgium: evidence of previous exposure to organochloride pesticides. Hum Reprod 2001; 16(5): 1020-1026.

4. Grumbach MM, Styne DM. Puberty: ontogeny, neuroendocrinology, physiology, and disorders. In: Wilson JD, Foster DW, Kronenberg HM, Larsen PR, Eds. William's Textbook of Endocrinology. Philadelphia: W.B. Saunders Company. 1998; 1509-1625.

5. Garn SM, Haskell JA. Fat and growth during childhood. Science 1959; 130: 1711-1712.

6. Marshall E. Epidemiology. Search for a killer: focus shifts from fat to hormones. Science 1993; 259(5095): 618-621.

7. Selevan SG, Rice DC, Hogan KA, Euling SY, Pfahles-Hutchens A, Bethel J. Blood lead concentrations and delayed puberty in girls. N Engl J Med 2003; 348(16): 1527-1536.

8. Blanck HM, Marcus M, Tolbert PE, Rubin C, Henderson AK, Hertzberg VS, Zhang RH, Cameron L. Age at menarche and Tanner stage in girls exposed in utero and postnatally to polybrominated biphenyl. Epidemiology 2000; 11(6): 641-647.

9. Proos LA, Hofvander Y, Tuvemo T. Menarcheal age and growth pattern of Indian girls adopted in Sweden. Acta Paediatr Scand 1991; 80(8-9): 852-858.

10. Krstevska-Konstantinova, Craen M, Beckers D, Du Caju M, Heinrichs C, de Beaufort C, Bourguignon JP. Growth pattern in idiopathic central precocious puberty: a comparison between Belgian native and adopted girls. 1998; Horm Res 50 (Suppl. 3): 130.

11. Krstevska-Konstantinova M, Craen M, Beckers D, Du Caju M, Heinrichs C, de Beaufort C, Bourguignon JP. Precocious puberty in adopted and non-adopted foreign girls moving to Belgium: a role for environmental factors independent of recovery from deprivation. 1999; Horm Res 51(Suppl 2): 71. 
12. Saenz de Rodriguez CA, Bongiovanni AM, Conde de Borrago L. An epidemic of precocious development in Puerto Rican children. J Pediatr 2000; 107(3): 393-396.

13. Natural Resources Defense Council. Environment and Health: Health Effects of Pollution: In Brief: FAQ, Endocrine Disruptors (http://www.nrdc. org/health/effects/ gendoc.asp).

14. National Toxicology Program, Center for Evaluation of risks to human reproduction. Final CERHR expert panel reports on 7 phthalate esters (http//cerhr, niehs,gov/ news/index. html). (Accessed March 23, 2003.)

15. McLachlan JA. Estrogenic properties of DDT and its analogs. In: McLachlan JA, ED. Estrogens in the Environment. New York: Elsevier/North-Holland. 1980; 239-263.

16. Tamir S, Eizenberg M, Somjern D, Stern N, Shelach R, Kaye A, Vaya J. Estrogenic and antiproliferative proglabridin from licorice in human breast cancer cells. Cancer Res 2000; 60(20): 5704-5709.

17. Kulin HE, Reiter EO. Gonadotropin and testosterone measurements after estrogen administration to adult men, prepubertal and pubertal boys, and men with hypogonadotropism: evidence for maturation of positive feed-back in the male. Pediatr Res 1976; 10(1): 46-51.

18. Mauras N, Rogol AD, Veldhius JD. Estrogenic modulation of the gonadotropin-releasing hormonestimulated secretory activity of the gonadotrope and lactotrope in prepubertal females with Turner's syndrome. J Clin Endocrinol Metab 1991; 73(6): 1202-1209.

19. Bitman J, Cecil HC, Harris SJ, Fries GF. Estrogenic activity of o,p'-DDT in the mammalian uterus and avian oviduct. Science 1968; 162(851): 371-372.

20. Gellert RJ, Heinrichs WL, Swerdloff RS. DDT homologues: estrogen-like effects on the vagina, uterus, and pituitary of the rat. Endocrinology 1972; 91(4): 1095-1100.

21. Clark EJ, Norris DO, Jones RE. Interactions of gonadal steroids and pesticides (DDT, DDE) on gonaduct growth in larval Tiger Salamanders, Ambystoma tigrium. Gen Comp Endocrinol 1998; 109(1): 94-105.

22. CharlierC. Endocrine effects of environmental pollutants. Bull Mem Acad R Med Belg 2005; 160(5-6): 301-310.

23. Brown NM, Lamartiniere CA. Xenoestrogens alter mammary gland differentiation and cell proliferation in the rat. Environ Health Perspect 1995; 103(7-8): 708-713.

24. Parent AS, Rasier G, Gerard A, Heger S, Roth C, Mastronardi C, Jung H, Ojeda SR, Bourguignon JP. Early onset of puberty: tracking genetic and environmental factors. Horm Res 2005; 64(Suppl 2): 41-47.

25. Rogan WJ, Ragan NB. Evidence of effects of environmental chemicals on the endocrine system in children. Pediatrics 2003; 112(1 Pt 2): 247-252.

26. Colon I, Caro D, Bourdony CJ, Rosario O. Identification of phthalate esters in the serum of young Puerto Rican girls with premature breast development. Environ Health Perspect 2000; 108(9): 895-900.

27. Den Hond E, Roels HA, Hoppenbrouwers K, Nawrot T, Thijs L, Vandermulen C, Winnecke G, Vanderschueren D, Staessen JA. Sexual maturation in relation to polychlorinated aromatic hydrocarbons: Sharpe and Skakkebaek's hypothesis revisited. Environ Health Perspect 2002; 110(8): 771-776.

28. Key T, Reeves G. Organochlorines in the environment and breast cancer. Br Med J 1994; 308(6943): 1520-1521.

29. Eddleston M, Karalliedde L, Buckley N, Fernando R, Hutchinson G, Isbister G, Konradsen F, Murray D, Piola JC, Senayake N, Sheriff R, Singh S, Siwach SB, Smit L. Pesticide poisoning in the developed world: a minimum pesticide list. Lancet 2002; 360(9430): 1163-1167.

30. National implementation plan on reduction and elimination of POPs in the Republic of Macedonia. Ministry of Environment and Physical Planning. 2004. 